\title{
A quantitative atlas of histone modification signatures from human cancer cells
}

\author{
Gary LeRoy ${ }^{1}$, Peter A DiMaggio², Eric Y Chan³, Barry M Zee1, M Andres Blanco', Barbara Bryant ${ }^{3}$, lan Z Flaniken 1 ,
} Sherry Liu ${ }^{4,5}$, Yibin Kang ${ }^{1}$, Patrick Trojer ${ }^{3}$ and Benjamin A Garcia ${ }^{4,5^{*}}$

\begin{abstract}
Background: An integral component of cancer biology is the understanding of molecular properties uniquely distinguishing one cancer type from another. One class of such properties is histone post-translational modifications (PTMs). Many histone PTMs are linked to the same diverse nuclear functions implicated in cancer development, including transcriptional activation and epigenetic regulation, which are often indirectly assayed with standard genomic technologies. Thus, there is a need for a comprehensive and quantitative profiling of cancer lines focused on their chromatin modification states.
\end{abstract}

Results: To complement genomic expression profiles of cancer lines, we report the proteomic classification of 24 different lines, the majority of which are cancer cells, by quantifying the abundances of a large panel of single and combinatorial histone H3 and H4 PTMs, and histone variants. Concurrent to the proteomic analysis, we performed transcriptomic analysis on histone modifying enzyme abundances as a proxy for quantifying their activity levels. While the transcriptomic and proteomic results were generally consistent in terms of predicting histone PTM abundance from enzyme abundances, several PTMs were regulated independently of the modifying enzyme expression. In addition, combinatorial PTMs containing H3K27 methylation were especially enriched in breast cell lines. Knockdown of the predominant H3K27 methyltransferase, enhancer of zeste 2 (EZH2), in a mouse mammary xenograft model significantly reduced tumor burden in these animals and demonstrated the predictive utility of proteomic techniques.

Conclusions: Our proteomic and genomic characterizations of the histone modification states provide a resource for future investigations of the epigenetic and non-epigenetic determinants for classifying and analyzing cancer cells.

\section{Background}

The search for the molecular properties that define cancer has provided important insights into the general cancerous state, as exemplified by the characterizations of commonly mutated tumor suppressors [1]. Yet cancer is not a single disease. Thus, it is not sufficient to only explore what broadly distinguishes the cancerous state from the otherwise healthy state. It is essential to identify in addition the molecular properties that distinguish

\footnotetext{
* Correspondence: bgarci@mail.med.upenn.edu

${ }^{4}$ Epigenetics Program, Perelman School of Medicine, University of

Pennsylvania, Smilow Center for Translational Research, 3400 Civic Center Blvd., Bldg 421, Philadelphia, PA 19104, USA

${ }^{5}$ Department of Biochemistry and Biophysics, Perelman School of Medicine, University of Pennsylvania, Smilow Center for Translational Research, 3400

Civic Center Blvd., Bldg 421, Philadelphia, PA 19104, USA

Full list of author information is available at the end of the article
}

a given class of cancer cells from another. By understanding both the general and specific properties defining cancer, one could design a comprehensive classification of cancer cells rooted in their underlying molecular biology and provide a resource useful for diagnosis and treatment.

Many of the properties that characterize cancer phenotypes operate at the genetic level, namely transcriptional states and gene mutations. Genomic approaches that collate gene expression patterns and catalog DNA sequence information have served as a vital platform for the profiling of a variety of cancer cells [2]. Absent from most genomic-based classifications of cancer is epigenetic information, which is a grasp of the physical in vivo state of genes. In eukaryotic cells, DNA typically exists in a complex with histones known as chromatin. Chromatin can be generalized as an array of tandem core

\section{Biomed Central}


nucleosomes individually composed of two copies each of histones $\mathrm{H} 2 \mathrm{~A}, \mathrm{H} 2 \mathrm{~B}, \mathrm{H} 3$ and $\mathrm{H} 4$ coiling approximately $147 \mathrm{bp}$ of DNA. The consequences of DNA existing in a complex with histones are enormous. First, electrostatic interactions between every $10 \mathrm{bp}$ of DNA and the histone octamer occlude various non-histone proteins from binding those nucleotides. Second, the stability of the nucleosome results in the need for ATP-dependent chromatin remodelers for the positioning and alteration in nucleosome structure. Because of these associations between histones and DNA, it is clear that many nuclear events, such as transcription, DNA damage repair and replication, are impacted by the nucleosome. It is also clear that these events broadly contribute to cancerous development when mis-regulated, for instance, the failure to detect or repair double stranded DNA breaks. Thus, an understanding of the cancerous state requires an understanding of the chromatin state.

Many correlations between DNA-dependent events and histones also occur at the level of histone posttranslational modifications (PTMs), namely lysine acetylation (ac), mono- (me1), di- (me2), and trimethylation (me3). Most histone PTMs do not alter nucleosome structure, rather the majority of PTMs are thought to recruit non-histone proteins via specialized PTM binding domains, such as the bromo, chromo and PHD domains. The binding of these non-histone proteins to chromatin can mediate many of the aforementioned events in a paradigm known as the histone code hypothesis [3]. For instance, trimethylated lysine 27 of histone H3 (H3K27me3) is recognized by Polycomb group (PcG) proteins, which maintain epigenetic silencing. Establishing this paradigm is the enzymatic regulation of histone modification states, such as histone acetyltransferases (HATs) and methyltransferases (HMTs), which acetylate and methylate histones respectively, and histone deacetylases (HDACs) and demethylases (HDMs), which convert the acetylated and methylated states, respectively, to the unmodified state. For example, H3K27me3 is formed by the EZH2 methyltransferase [4].

Between histone-modifying enzyme activities that regulate histone PTM states and histone-binding proteins that effect DNA-dependent processes, cancer development has been linked to histone modifications at various levels [5]. One example linking cancer with a histone PTM-binding protein includes associations between bromodomain-containing BRD3 and BRD4 proteins, which recognizes histones $\mathrm{H} 4$ acetylated at $\mathrm{K} 5$, $\mathrm{K} 8$ and $\mathrm{K} 12$ [6], and PAFC and SEC elongation factors in MLL fusion leukemias [7], as well as translational fusions between BRD4 and NUT proteins in certain squamous carcinomas $[8,9]$. An example linking cancer with a histone PTM modifying enzyme protein would be the commonly observed mutations in EZH2 HMT in certain lymphomas and myelodysplastic syndromes that reduce the catalytic activity to trimethylate H3K27 [10,11]. What these examples emphasize is that first, despite the pervasive nature of histone PTMs, specific cancer phenotypes arise from alterations in the chromatin PTM landscape and, second, there may potentially be many other histone modifications of equal or greater importance in cancer biology.

Given the relevance of histone PTMs to cancer, heretofore understood primarily using low-throughput and often inferential approaches, there is a need for a comprehensive profiling of cancer cells concentrated specifically on their chromatin modification states. Here we applied mass spectrometry-based proteomic techniques to quantify global abundances of histone PTMs from 24 commonly used cell lines, the majority of which are of cancerous lineages. Additionally, we applied microarray-based genomic techniques to monitor transcript levels of various histone-modifying enzymes. The proteomic and transcriptomic analyses were generally consistent in classifying which lines were similar, based on their chromatin PTM patterns and chromatin modifying enzyme levels, respectively. Among our results, H3K27 methylation was highly increased in breast cancer cells. Moreover, depletion of EZH2 led to decreased tumor formation in a mouse xenograft model, consistent with the known role of EZH2 in the pathogenesis of other cancers. In summary, this study constitutes an "atlas" of histone PTMs across the reported lines, and using this atlas, one may potentially attain a novel molecular classification of cancer cells based on their chromatin modification landscape. We believe this dataset will motivate future studies in the cancer chromatin field.

\section{Results}

\section{A chromatin atlas of cancer lines quantifying transcript} levels of chromatin-modifying enzymes

For our chromatin-centric atlas, we examined 24 cell lines from a diverse variety of tissue origins, including cervix, prostate, lung and breast tissues (Table 1). The majority of these lines are cancer cells, and the remaining non-cancer lines include 293, HFF, HaCAT and hESC cells. To explore whether different cell lines would possess different chromatin profiles, we harvested RNA from all the lines and performed gene expression analysis using a custom microarray with multiple probes to 224 human HATs, HDACs, HMTs and HDMs (Figure 1).

Our hypothesis is that differences in the chromatin state can potentially give rise to the distinguishing characteristics of cancer cell lines. Indeed, cell lines that originate from a common tissue type generally cluster together (Figure 1). The two breast lines in our study, 
Table 1 Tissue culture cell lines used in this study

\begin{tabular}{|c|c|c|}
\hline Cell line & Media & Comment \\
\hline 1. 293 & DMEM & Embryonic kidney \\
\hline 2. A549 & DMEM & Adenocarcinomic alveolar basal epithelial \\
\hline 3. C33a & DMEM & Cervical carcinoma \\
\hline 4. DUT145 & DMEM & Prostate cancer \\
\hline 5. $\mathrm{H} 1229$ & RPMI & Lung carcinoma \\
\hline 6. HaCAT & RPMI & Immortalized, non-tumorigenic keratinocyte \\
\hline 7. HCT116 & McCoy 5A & Colorectal carcinoma \\
\hline 8. HeLa & Joklik & Cervical carcinoma \\
\hline 9. hESC2 & DMEM & Human embryonic stem cells \\
\hline 10. HFF & DMEM & Human foreskin fibroblasts \\
\hline 11. HL60 & IMM & Promyelocytic leukemia cells \\
\hline 13. Huh7.0 & DMEM & Hepatocarcinoma \\
\hline 14. Huh7.5 & DMEM & Hepatocarcinoma (RIG-I-deficient) \\
\hline 14. MCF7 & DMEM & Breast carcinoma \\
\hline 15. MDaMB231 & L15 & Breast carcinoma \\
\hline 16. Mdm13 & DMEM & Monocyte-derived macrophages \\
\hline 17. NB4 & RPMI & Acute promyelocytic cell line \\
\hline 18. PANC1 & DMEM & Pancreatic carcinoma, epithelial-like \\
\hline 19. PC3 & DMEM & Prostate cancer \\
\hline 20. SAOS & McCoy 5A & Epithelial-like osteosarcoma cell line \\
\hline 21. SW480 & L15 & Colon adenocarcinoma \\
\hline 22. U2OS & DMEM & Osteosarcoma \\
\hline 23. U251 & DMEM & Glioblastoma \\
\hline 24. U937 & RPMI & Leukemic monocyte lymphoma \\
\hline
\end{tabular}

MCF7 and MDA-MB231, exhibited similar expression profiles across the histone modifying enzymes (Wilcoxon sign rank, zval $=-0.9207, P=0.3572$ ). While it may be expected that two lines from different tissue types have significantly different expression profiles, for instance, between MDA-MB231 and the leukemia HL60 line (Wilcoxon sign rank, $\mathrm{zval}=-4.2728, \quad P=1.9305 \times 10^{-5}$ ), some lines from different tissue types have similar expression profiles. For instance, similar profiles were observed between the HEK293 line and the U2OS cell line (Wilcoxon sign rank, zval $=-1.7466, P=0.0807$ ) to a modest extent and between the cervical HeLa line and the PC3 prostate line (Wilcoxon sign rank, $\mathrm{zval}=-1.5303, P=$ 0.1259 ). What these results suggest is that the expression levels of chromatin modifying enzymes alone are insufficient for distinguishing chromatin modification patterns between cancer cell lines, and that other factors may regulate the activity of these enzymes, such as post-translational modifications of the chromatin modifying enzymes, themselves likely influence the chromatin state [12]. Moreover, these results also suggest that cancers of distinct origins may have similar transcriptomic profiles, which should be helpful when considering treatment options.

\section{Quantification of histone PTM abundances for a complementary proteomic atlas}

The 24 cell lines exhibited a diverse range of gene expression patterns for the various histone modifying enzymes. Although gene expression analysis revealed both expected and unexpected correlations across the lines, a critical limitation of such analyses is the inability to extrapolate enzyme activity from enzyme transcript abundance. It is the activity of the chromatin modifying enzymes that is most informative for designing an accurate classification of cell lines based on their chromatin states. Thus, to complement our transcriptomic analysis, our strategy to extrapolate enzyme activity was to determine the abundances of the enzyme substrates and enzyme products, namely the steady state histone PTM levels.

In order to determine the relative abundances of histone modifications for each line, we utilized our Bottom Up MS protocol, which has also been adapted by multiple laboratories [13-15]. Here, we generated ArgC-like fragments from acid-extracted histones and analyzed the peptides on a hybrid Orbitrap-linear ion trap quadrupole mass spectrometer (ThermoFisher Scientific, Carlsbad, CA, USA) (Figure 2). With this approach, we reproducibly obtained greater than $90 \%$ sequence coverage for histones $\mathrm{H} 3$ and $\mathrm{H} 4$ and were able to quantify 37 unique histone modification patterns on histone $\mathrm{H} 3$ and 19 patterns on histone $\mathrm{H} 4$ across every cell line (Additional file 1). We normalized all detected PTMs or modified forms of a common peptide backbone to each other. For instance, we would normalize the measured abundances of all the observable modified forms of the 9 to 17 histone H3 peptide (KSTGGKAPR), which spans lysine 9 and lysine 14, against each other. The normalization would occur independently of all observed modified forms of another histone peptide, such as the 18 to 26 peptide (KQLATKAAR). Because of our normalization, our PTM values for a given peptide backbone are not necessarily independent of each other. Thus, for $n$ modified forms of a given peptide, there are $n-1$ degrees of freedom. Because we quantified five different histone $\mathrm{H} 3.1 / \mathrm{H} 3.2$ peptide backbones: namely the 3 to 8 peptide TKQTAR, the 9 to 17 peptide KSTGGKAPR, the 18 to 26 peptide KQLATKAAR, the 27 to 40 peptide KSAPATGGVKKPHR, and the 73 to 83 peptide EIAQDFKTDLR, we have $n-5$ degrees of freedom along the histone H3 PTM axis. Here we have supplied the normalized values not only in terms of fold enrichment, but also relative abundance, thus one can gauge the significance of the change based on the magnitude of the PTM abundance. Additionally, lower abundance marks require greater fold change to be deemed significant and, conversely, higher abundance marks require lower fold change to be deemed significant. 


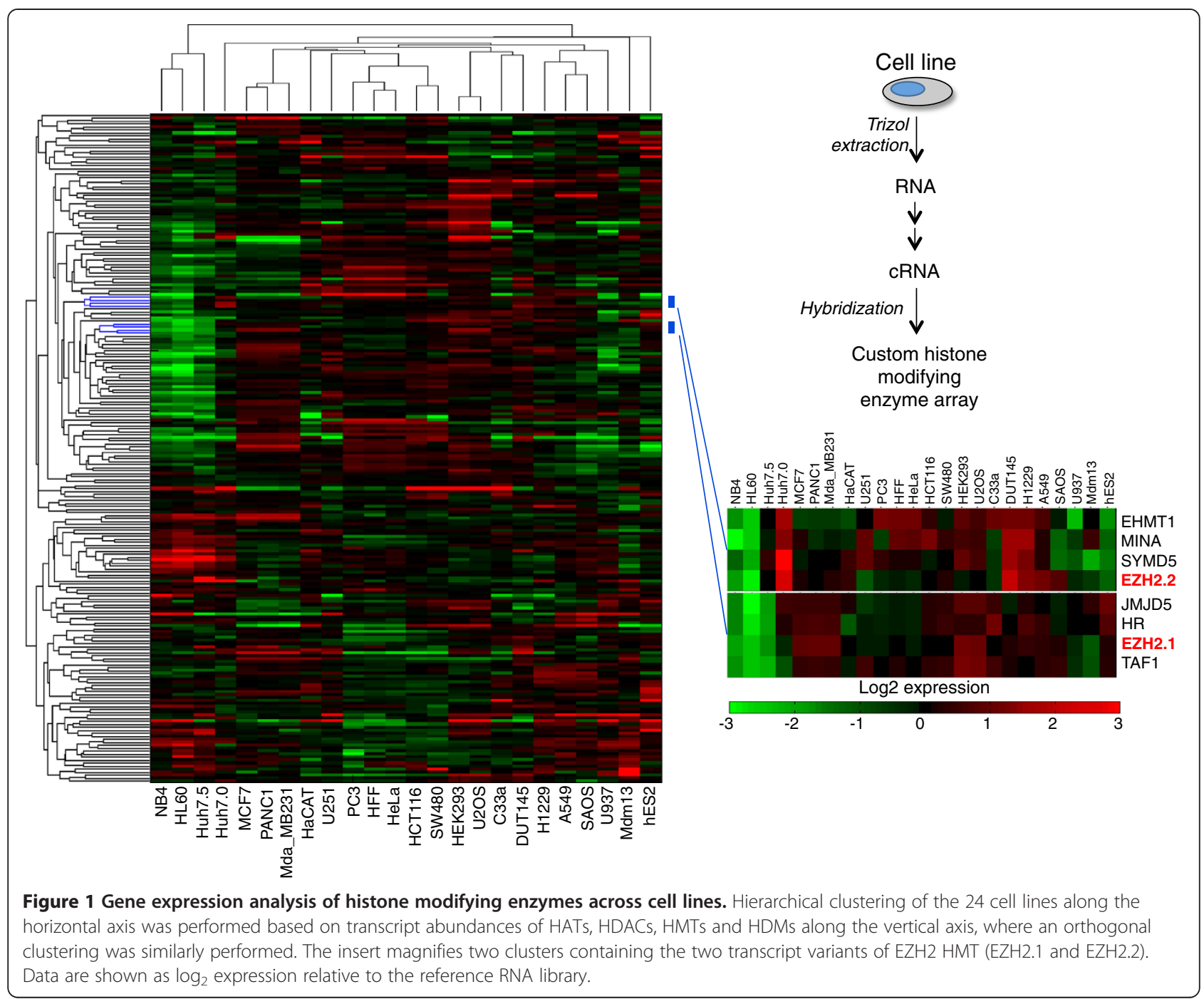

\section{A chromatin atlas of cancer lines focused on relative levels of chromatin modifications}

We report the modification levels on histone H3 (Figure 3) and histone H4 (Figure 4) for each of the 24 cell lines across the average relative abundance of all the lines. For example, we determined the enrichment of the relative abundance of H3K27me3K36un for MCF7 against the average relative abundance of $\mathrm{H} 3 \mathrm{~K} 27 \mathrm{me} 3 \mathrm{~K} 36 \mathrm{un}$ across the 24 lines. The actual and average relative abundances for each line are also provided (Additional file 1). Analogous to the transcriptomic analysis, cell lines of similar tissue origin have similar chromatin modification profiles. For instance, enrichment of a given PTM in the breast line MCF7 is generally accompanied with similar enrichment of the same PTM in the other breast line MDA-MB231 (Figure 3). In particular, the differences in PTM relative abundance between the Huh7.0 and Huh7.5 were comparable to the differences between MCF7 and MDAMB231 (Wilcoxon sign rank, $\mathrm{z}=-0.0830, P=0.9339$ ) and between A549 and H1229 (Wilcoxon sign rank, z = -0.3093, $P=0.7571$ ). In contrast, the differences in PTM abundances between PANC1 and NB4 was significantly greater than the differences between Huh7.0 and Huh7.5 (Wilcoxon sign rank, $z=-4.5334, P=5.8034 \times 10^{-6}$ ), implying that PANC1 and NB4 have different chromatin modification profiles. Yet there were exceptions to the generality that lines of different tissue origins will have different histone PTM patterns. For instance, the differences between SAOS and U251 were comparable to the differences between MCF7 and MDA-MB231 (Wilcoxon sign rank, $\mathrm{z}=-0.2640, P=0.7918$ ) and Huh7.0 and Huh7.5 (Wilcoxon sign rank, $\mathrm{z}=-0.5959, P=0.5512$ ), implying a similar chromatin modification profile of the SAOS and U251 lines despite originating from different tissues.

Applying our analytic software, we successfully quantified the 9 to $17 \mathrm{H} 3$ peptides (KSTGGKAPR) containing serine 10 phosphorylation that otherwise would be difficult to quantify manually due to their low abundance. In 


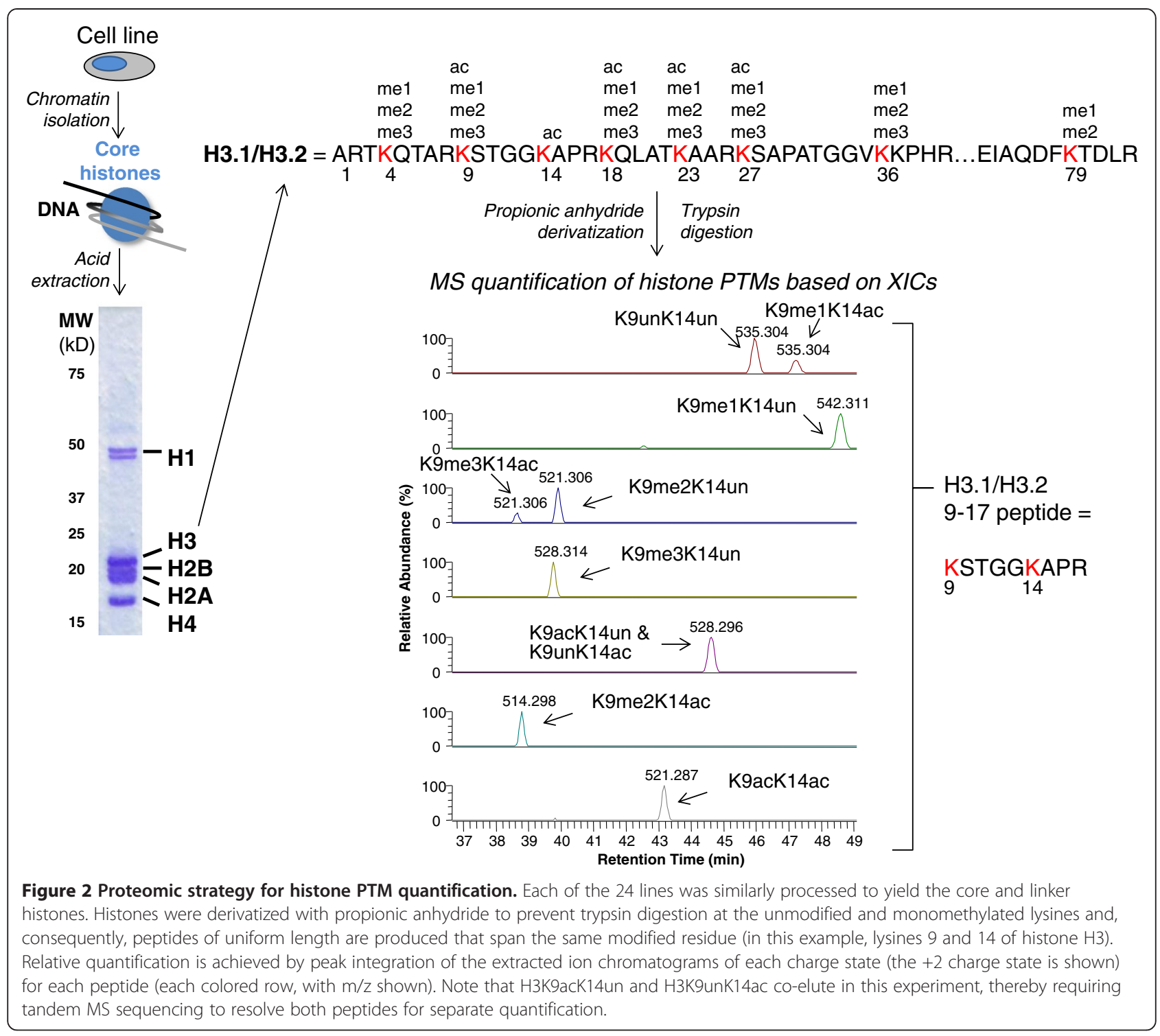

general, most of the 24 lines had less than $1 \%$ total occurrence of H3S10 phosphorylation, with the notable exceptions of Panc1, Huh7.0 and Huh7.5 that contain 4.4, 3.7 and $4.3 \%$ relative abundance of phosphorylated peptides, respectively (Additional file 2). Since the cell lines were not synchronized across the cell cycle, we hypothesize that the levels of H3S10 phosphorylation proportionately reflect the percentage of cells in an asynchronous population that were in $\mathrm{M}$ phase at the time of harvest. Furthermore, when we compared the modification states of H3K9 and H3K14 depending on the modification state of H3S10, we observed that the H3K9 and H3K14 modification patterns differed based on the phosphorylation state of H3S10. In particular, H3S10 phosphorylation generally co-occurred with H3K9me3K14un, even when this modification is not particularly abundant for a given line (Additional file 2). It is possible that this trend reflects the methyl-phospho switch model [16], which proposes that a key function of H3S10 phosphorylation is to block HP1 from binding to H3K9me2 or H3K9me3. Thus, H3S10ph would be expected to co-occur more often with H3K9me2 and H3K9me3 (that is, H3K9me2S10ph and H3K9me3S10ph) than with H3K9un and H3K9me1, which we observed.

Our histone $\mathrm{H} 4$ characterization focused on lysines 5 , 8,12 and 16 acetylation and lysine 20 mono-, di- and trimethylation (Figure 4). We observed that various cell lines, namely C33a, hESC2, HCT116 and U2OS, contained elevated levels of histone $\mathrm{H} 4$ acetylation, such as the tetra-acetylated H4K5acK8acK12acK16ac form and H4K5unK8unK12acK16ac. Enrichment for specific acetylated patterns may have interesting implications for Brd2, Brd3 and Brd4 recruitment, as discussed later. In contrast, another set of lines, namely the MCF7, 


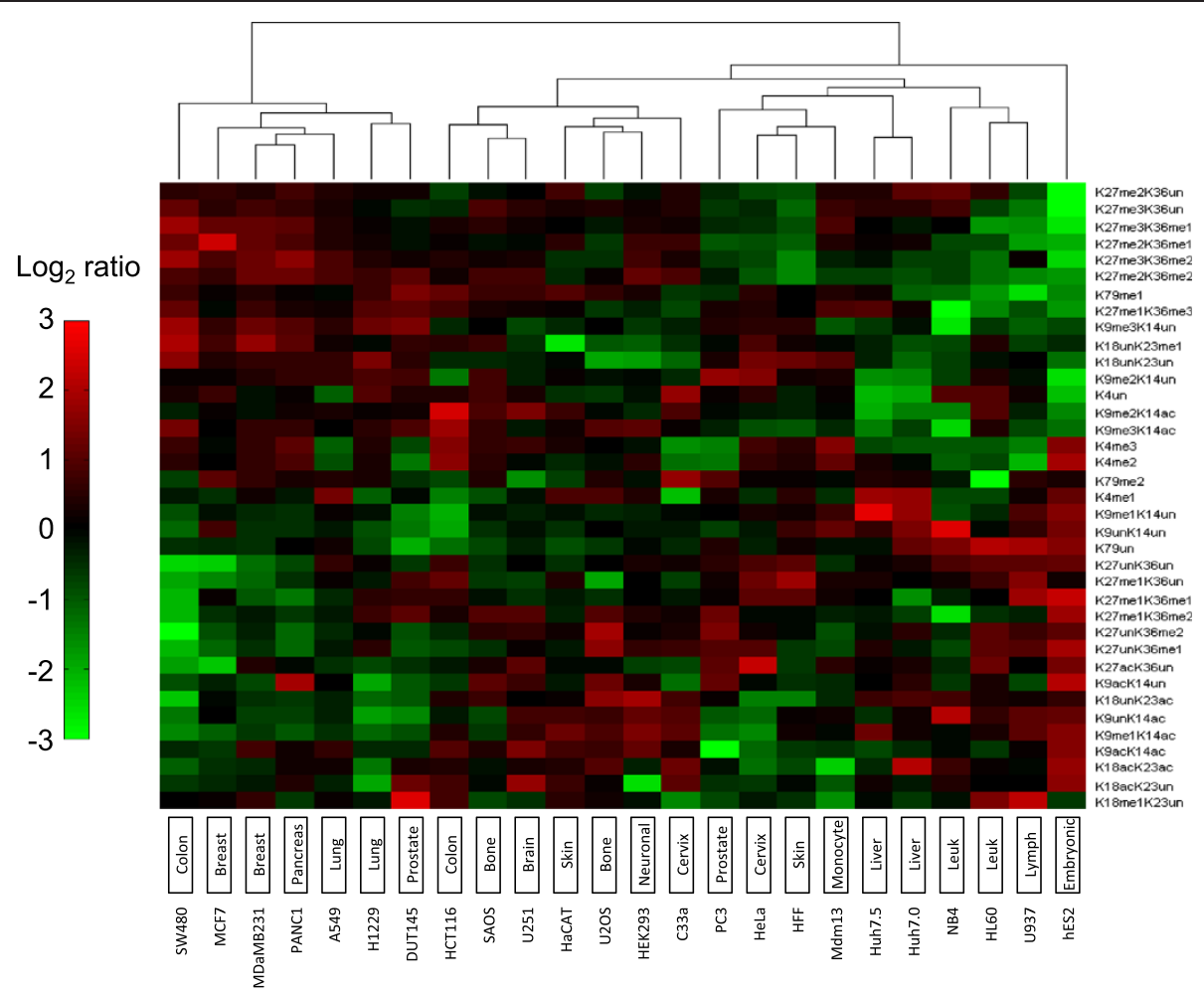

Figure 3 Proteomic analysis of histone H3 PTMs across cell lines. Hierarchical clustering of the 24 lines was performed based on abundances of histone H3 PTMs (shown in right vertical axis). Cell line tissue type is shown in the bottom horizontal axis. Data shown as $\log _{2}$ enrichment of histone PTM levels for a given line (biological replicates of 3 to 7) based on average PTM levels across all 24 lines.

MDA-MB231 and SW480, has depleted levels of histone $\mathrm{H} 4$ acetylation. It is interesting to recall that these same three cell lines also were enriched in H3K27 methylation and depleted in H3K9ac, H3K18ac and H3K23ac (Figure 3).

Finally, we briefly report our approximation of the distribution of $\mathrm{H} 2 \mathrm{~A}$ variants across the 24 lines (Additional file 3). There was little difference in abundance of macroH2A and H2AZ among most cell lines, although the trend suggests a greater abundance of $\mathrm{H} 2 \mathrm{~A}$, in general, over macroH2A. For instance, H1229 (Wilcoxon rank sum, $\mathrm{z}=2.6421 P=0.0082$ ) and hESC (Wilcoxon rank sum, $\mathrm{z}=2.8022, P=0.0051)$ possessed significantly more $\mathrm{H} 2 \mathrm{AZ}$ than macroH2A. A notable exception is MDM13, which has significantly higher levels of macroH2A relative to H2AZ (Wilcoxon rank sum, $\mathrm{z}=-2.1651, P=0.0304$ ).

\section{Integration of both genomic and proteomic chromatin classifications of cell lines}

In general, the genomic classification of the 24 lines was consistent with the proteomic classification of the 24 lines. Lines with similar expression profiles would generally have similar histone PTM patterns, and conversely, lines with distinct expression profiles would generally have distinct histone PTM patterns. Interestingly, the shortest-link clusters in the microarray data correlate well with the shortest-link clusters in the histone H3 PTM data. Specifically, the clusters (1) HEK293 and U2OS, (2) HFF, HeLa and PC3, and (3) MCF7, PANC1 and MDA-MD231 from the microarray data (Figure 1) reappear as clusters in the histone $\mathrm{H} 3$ PTM data (Figure 3). This consistency suggests that in these cell lines the mRNA levels of the histone modifying enzymes correlates well with their levels of enzymatic activity.

What one can learn uniquely from both the transcriptomic and proteomic experiments is to crosscorrelate the expression levels of every histone modifying enzyme with the enrichment of every histone PTM across all 24 lines (Figure 5). The aim of such an analysis is to identify histone PTMs positively or negatively coregulated by a particular enzyme. Not only should such cross-correlation procedures map particular modifications for a given enzyme with the histone residues it is known to modify, but also this approach should reveal novel modification sites targeted by a given enzyme in vivo. We further analyzed the expression profiles by bi-clustering [17] within individual cell line-clusters in Figure 1 to extract correlative behavior across different cell lines. For instance, re-clustering the expression profiles over only HEK293 and U2OS (the shortest link cluster in Figure 1) 


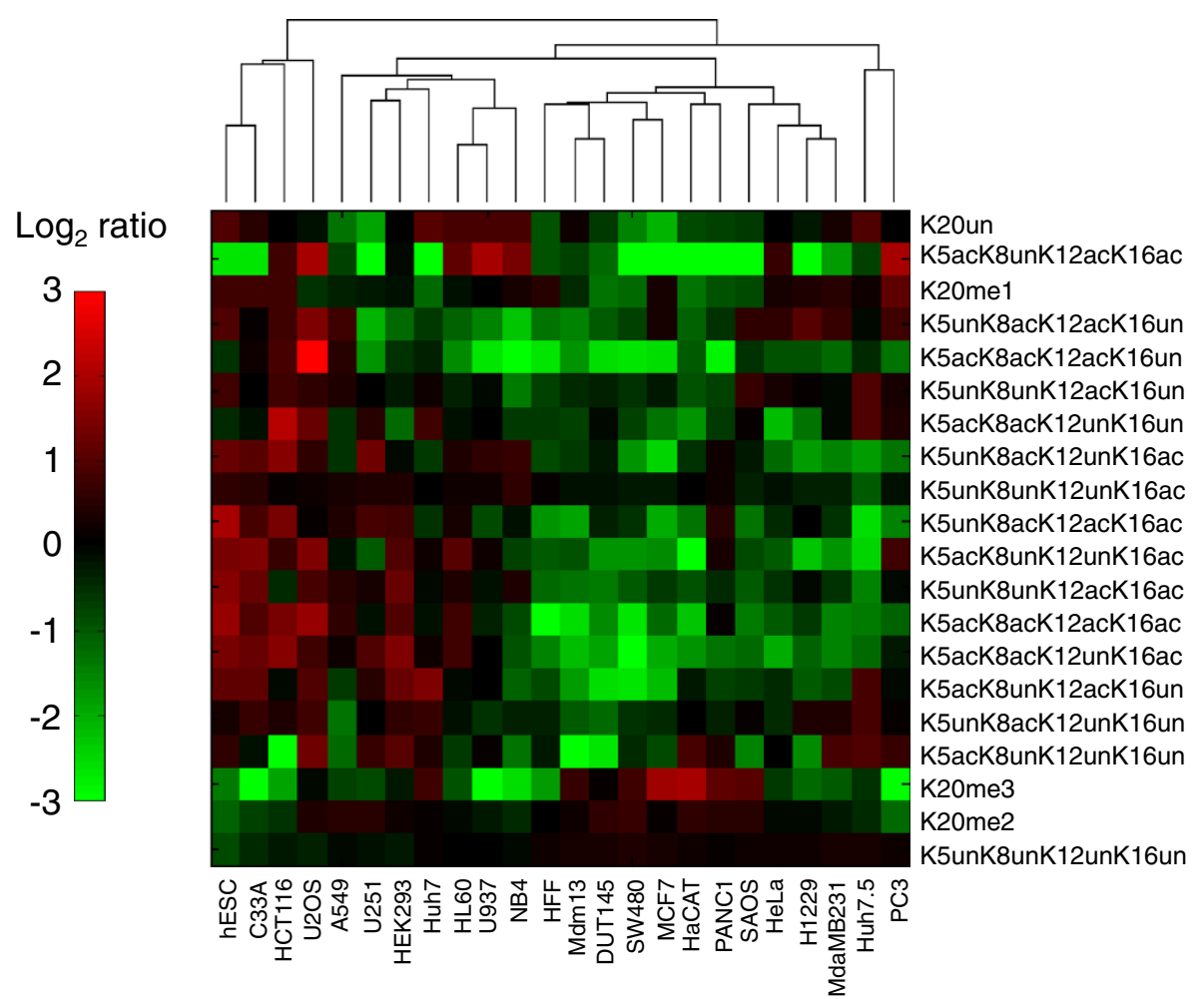

Figure 4 Proteomic analysis of histone H4 PTMs across cell lines. Hierarchical clustering of the 24 lines was performed based on abundances of histone H4 PTMs (shown in right vertical axis). Data are shown as $\log _{2}$ enrichment of histone PTM levels for a given line based on average PTM levels across all 24 lines.

reveals that MYST1 and CDY1, both H4 HATs, are among the highest expressed transcripts for these two cell lines (Additional file 4). This finding is consistent with the observed increase in $\mathrm{H} 4$ acetylation in the U2OS (Figure 4).

A very similar result is obtained when bi-clustering over only HCT116 and SW480 (two colon cancer cell lines clustered together in Figure 1), where over an eight-fold increase in the H4 HATs CDY1 and HAT1 is observed (Additional file 5), and notably HCT116 is found to be enriched in $\mathrm{H} 4$ acetylation (Figure 4). Bi-clustering the expression profiles over the PC3, HFF and HeLa cell linecluster reveals significant yet consistent changes in HMTs within these cells lines (Additional file 6). In particular, SETD6, PRDM5 and PRDM15 are the most significantly over-expressed (over 3.5-fold) and PRDM12, MLL2 and SUV420H1 are the most significantly under-expressed (over 3.5-fold) across all 224 transcripts. Several interesting patterns are also observed when bi-clustering the expression profiles within the breast cancer-rich cluster (that is, clustering only within the MCF7, PANC1, MDA-MB231 cell lines). Within these cell lines, a number of HMTs are found to be consistently and significantly up-regulated (Additional file 7). Namely, SUV420H1 (H4K20me), MLL2 (H3K4me), WHSC1 (H4K20me, H3K36me2), PRDM16 (H3K9me1), MECOM (H3K9me1), EZH2 (H3K27me2/3) and NSD1 (H3K36me) are all observed to exhibit higher expression levels in the MCF7, PANC1 and MDAMB231 cell lines. The later pair of HKMTs, EZH2 and NSD1, are particularly interesting as these cell lines also exhibit the greatest increase in the hypermethylated states of H3K27K36 (that is, H3K27me2K36me2, H3K 27me3K36me2, H3K27me2K36me1 and H3K27me3 K36me1 are the most abundant in these cell lines in Figure 3). This correlative behavior between EZH2 and NSD1 potentially suggests a direct or indirect functional relationship between the two methyltransferases. Conversely, within the same cell lines there is a substantial decrease in the HATs GTF3C4 (H3K14ac), MYST1 (H4K16ac) and CDY1 (H4ac), and this is consistent with the observed decrease in $\mathrm{H} 4$ acetylation in the MCF7 and MDA-MB231 breast cancer cell lines (Figure 4).

As highlighted in the bi-clustering analysis, one of the more striking observations is that the two breast cell lines in our collection, namely MCF7 and MDA-MB231, are equally well characterized by both histone PTMs and the expression level of the associated enzymes. In particular, histone marks that were relatively enriched in the two cell lines, such as H3K27me3K36me1 and H3K9me3K14un, were also positively correlated with EZH2 expression. Interestingly, EZH2 is also positively correlated with 


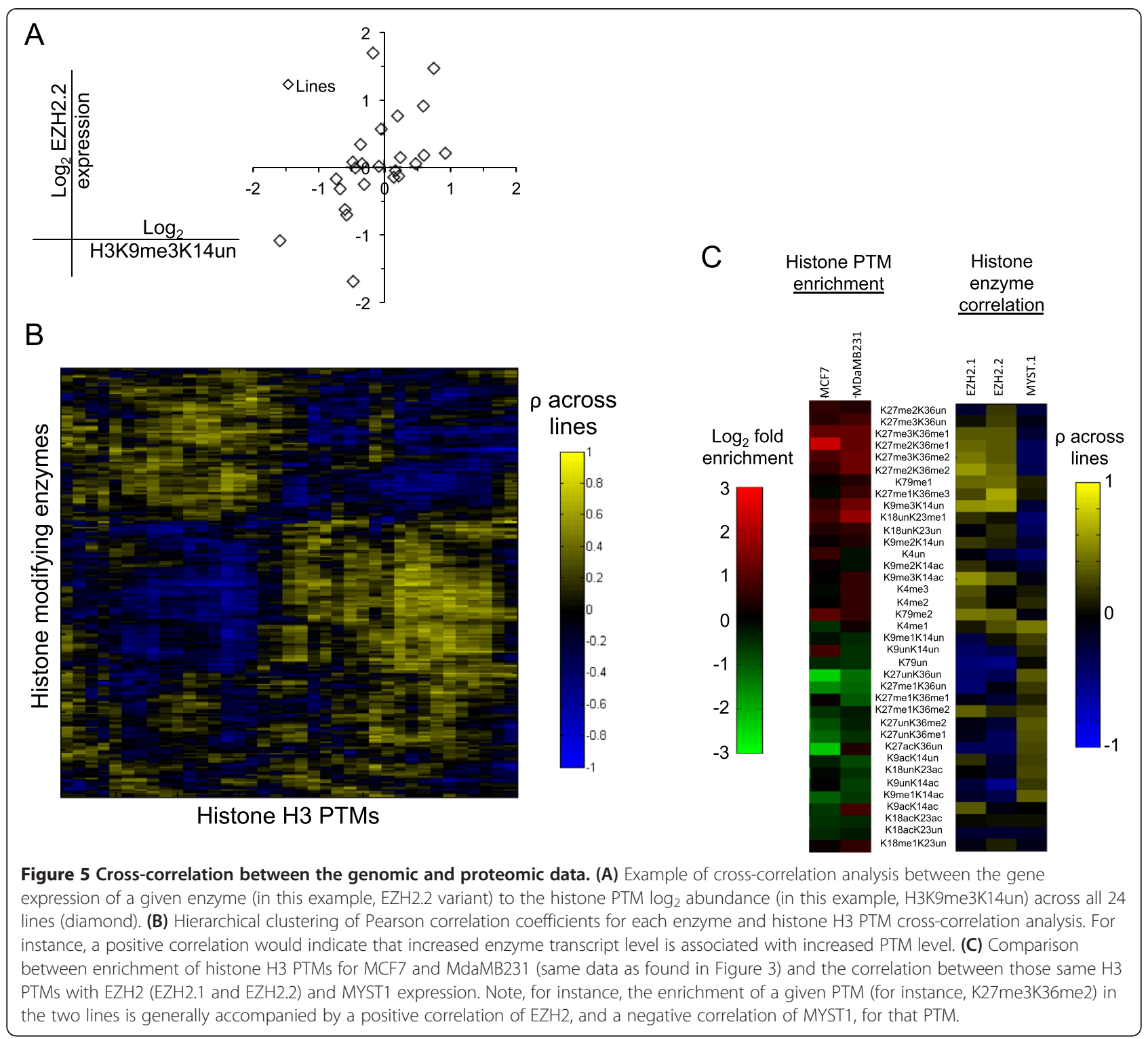

H3K9me3K14un and H3K9me3K14ac, which may reflect binding of polycomb repressive complex PRC1 (which does not contain EZH2 HMT) with H3K27me3 and $\mathrm{H} 3 \mathrm{~K} 9 \mathrm{me} 3$, as previously documented. It has been suggested that SUV39H1, an H3K9 methyltransferase, plays a role in targeting the PCR1 complex to H3K27me3 [18]. A more recent study analyzing the function of EZH2 in breast and prostate cancer lines has reported that the recruitment of EZH2 and Suz12 (both PRC2 subunits) to the promoter region of the tumor-suppressor gene RKIP is accompanied by H3K27 and H3K9 trimethylation [19]. These two studies support our observed correlation between the methylation levels on H3K9 and Н3К27, particularly within the context of breast and prostate cancer.
As a reference, nearly the opposite correlations were observed for MYST1, a HAT reported to acetylate H4K16. MYST1 is negatively correlated with the aforementioned marks yet positively correlated with H3K27acK36un and H3K9acK14un. Indeed, this correlation makes sense from what is currently known regarding the relationship between histone PTMs and active gene transcription, as $\mathrm{H} 4 \mathrm{~K} 16 \mathrm{ac}$ is implicated in transcriptional elongation [20], and $\mathrm{H} 3 \mathrm{~K} 27 \mathrm{ac}$ and $\mathrm{H} 3 \mathrm{~K} 9 \mathrm{ac}$ are marks that associate with active regulatory regions [21]. Taken together, our data point to the possibility that mammary cancer cells share a chromatin state characterized by elevated H3K27me3 levels and EZH2 expression. This suggested to us that EZH2 would be a particularly attractive candidate to investigate with respect to these two breast cancer cell lines. 


\section{H3K27 methylation levels affect tumor formation in a mouse xenograft model}

One of the most salient results from the proteomic atlas of chromatin modifications is enrichment of $\mathrm{H} 3 \mathrm{~K} 27 \mathrm{me} 3$ in the MCF7 and MDA-MB231 breast lines. The functional roles of H3K27me3 and EZH2 in cancer progression are incompletely understood, as EZH2 has been proposed to both promote and oppose cancer formation and progression. From our profiling of 24 different cell lines and from the observed influence of H3K27me status on overall clustering, we hypothesized that lines most enriched for H3K27me3 would be especially reliant on this modification for their tumorigenicity. To test this hypothesis and validate our approach experimentally, we performed in vivo mouse xenograft tumorigenesis assays. Here, we stably knocked down EZH2 in MDA-MB231 cells and injected control or KD cells into the mammary fat pads of nude mice. Assessing tumor burden via noninvasive, quantitative bioluminescent imaging, we observed a striking loss of tumorigenicity in EZH2-KD compared to control cells (Figure 6). While breast tumors formed by control cells grew rapidly, reflecting the aggressive nature of MDA-MB231 cells, EZH2-KD cells either formed modest tumors with reduced growth rates or failed to initiate tumors altogether. Overall, these results confirm the role of EZH2 in promoting breast cancer tumorigenesis. More specifically, the magnitude of the observed phenotype suggests that cell lines, such as MDAMB231, which harbors strongly elevated H3K27me3 levels, absolutely require high EZH2 activity for their ability to initiate and sustain malignancies.

\section{Discussion}

In this report, we provide a proteomic atlas of cancer lines based on histone modification patterns, and a companion genomic atlas of the same lines based on expression of histone modifying enzymes. The primary advantages of microarray procedures, in the context of this and similar experiments, are minimal requirement for sample cell amount and unsurpassed high-throughput quantification of enzyme transcripts. The primary advantage of MS procedures is the ability to extrapolate the catalytic activity of those enzymes by quantifying at the protein level the abundances of the histone modifications themselves that are the products and substrates for the enzymes. Although not as sensitive as antibody-based characterization of histone modifications, MS procedures offer a highly quantitative, unambiguous and generally unbiased identification of
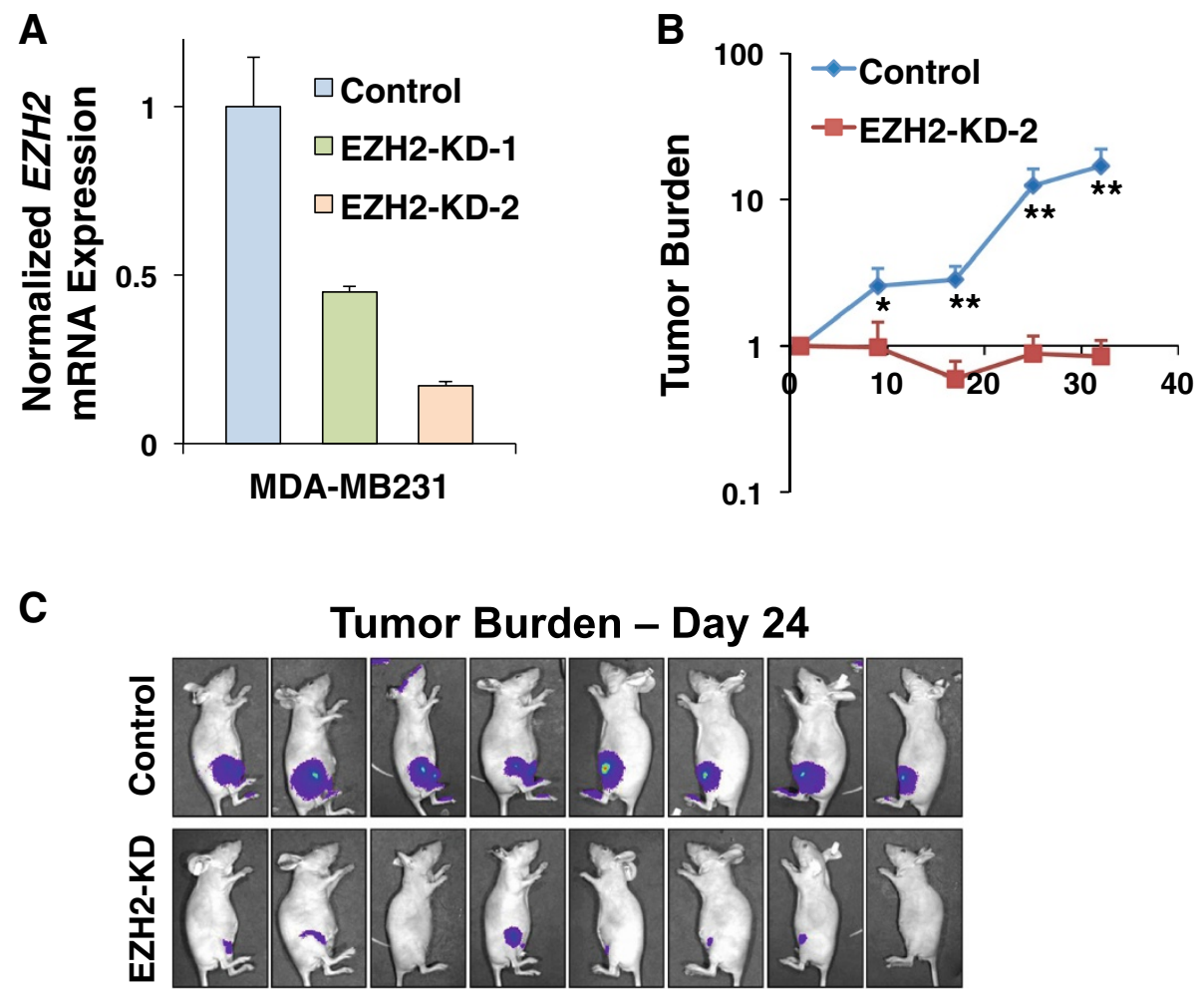

Figure 6 EZH2 promotes breast cancer tumorigenesis in vivo. (A) EZH2 was stably knocked down via shRNA in MDA-MB-231 cells. Knockdown efficiency was assessed via quantitative RT-PCR. (B) Control or EZH2-KD MDA-MB-231 cells were xenografted into mammary fat pads of nude mice and tumor burden was quantified over time via weekly bioluminescent imagine (BLI). BLI signals are normalized to the Day 1 signal for each mouse. (C) Images of mice injected with control or EZH2-KD cells are displayed (24 days post-injection). Data are shown as the mean + SD (RT-PCR) or mean + SEM (xenografts). ${ }^{*} P<0.05$; ${ }^{* * P}<0.01$. 
histone modifications that often cannot be easily controlled for otherwise [22,23]. Other studies comparing cancer types have similarly taken advantage of proteomic approaches to characterize chromatin modification patterns [24-26].

Our findings are generally consistent with other reports that interrogated specific PTMs in certain cancers (Table 2). For instance, various cancers, including HL60, HCT116 and primary non-tissue culture cancers, have been reported to have low levels of H4K16 acetylation and H4K20me3 with respect to normal tissue [26]. Although our analysis does not provide an immediate comparison to normal tissue, we observed a general depletion of H4K20me3, although notably not in H4K16 acetylation in both HL60 and HCT116 (Figure 4). As another example, non-small cell lung cancers have been reported to have low levels of H3K9ac and H4K16ac [27]. Likewise in this study, one of our lung lines H1229 had reduced levels of H4K16ac independent of the acetylation states of $\mathrm{H} 4 \mathrm{~K} 5, \mathrm{~K} 8$ or $\mathrm{K} 12$, and reduced levels of both H3K9acK14un and H3K9acK14ac. Yet, there is a considerable level of inconsistency among reports on histone modification levels, for instance, whether low levels of H3K18ac are linked to negative [28] or positive [29] prognosis. Much of the variability could be due to heterogeneity of cancer cells from patients or differences in methods [30].

Our results are in slight contradiction with what was observed in an immunohistochemistry study of the global Ezh2 and H3K27me3 levels in breast cancer tumors and cell lines [39], where Mda-MB231 (claudin-low subtype, ER-negative) was reported to have moderate expression of both EZH2 and H3K27me3, but MCF-7 (luminal subtype, ER-positive) was reported to have low expression of both EZH2 and H3K27me3. The differences between our results and this study could potentially be due to differences in the methodology used. Nonetheless, our findings support the observed overexpression of Ezh2 in breast and prostate cancer [19], as DUT145, a prostatic adenocarcinoma, was observed to exhibit significant overexpression of Ezh2.2 (Figure 1) and belongs to the cluster of tissues with elevated H3K27me3 levels (Figure 3). Our ability to specify combinatorial modifications using mass spectrometry provides a dimension of the data that is nearly intractable from previous reports yet is an important consideration especially for the design of pharmacological inhibitors. Various inhibitors targeting histone PTM binding proteins have been reported to have therapeutic effect towards specific cancers, for instance, the JQ1 molecule inhibiting Brd4 binding to histone H4 [9]. Another example illustrating the relevance of combinatorial histone modifications is the estrogen receptor coactivator TRIM24, which is overexpressed in breast cancer and associates with the specific combinatorial pattern H3K4unK23ac [40]. The methods utilized in this report could be of considerable importance in designing new small molecules to compete in vivo with specific histone modification patterns and in assaying how inhibition of a specific histone PTM binding or modifying protein would impact other histone modification abundances on a genomic scale.

Recently, there have been several fatty acyl PTMs discovered on histones, including lysine crotonylation, and other marks, such as lysine succinylation or malonylation $[13,41]$. These types of modifications have been observed by our mass spectrometry methodology, but they are extremely low level. We estimate that these marks, such as crotonylation, are found in most cell types as low as $0.01 \%$

Table 2 Comparison between several observed histone PTM levels in this study and other studies (Chervona and Costa 2012)

\begin{tabular}{|c|c|c|}
\hline Histone modification & Observation in this study & Observation in other studies \\
\hline H3K4me3 & Elevated in HCT116 colon line & Elevated SMYD3 HMT levels in colorectal carcinomas [31] \\
\hline H3K9me3 & Reduced in NB4 and HL60 leukemia lines & Reduced in promoter regions of acute myeloid leukemia patients [32] \\
\hline $\begin{array}{l}\text { H3K9me3 and } \\
\text { H3K9me3K14ac }\end{array}$ & $\begin{array}{l}\text { Elevated in MDA-MB231 and MCF7 breast } \\
\text { lines }\end{array}$ & Elevated in circulating nucleosomes of breast cancer patients [33] \\
\hline H3K18acK23un & $\begin{array}{c}\text { Reduced in } 293 \text { kidney and H1229 lung } \\
\text { lines }\end{array}$ & Reduced in poor prognosis kidney and lung cancer patients [34] \\
\hline H3K27me3 & Elevated in SAOS bone line & Elevated EZH2 HMT expression in osteosarcomas [35] \\
\hline H3K27me3 & $\begin{array}{l}\text { Elevated in MDA-MB231 and MCF7 breast } \\
\text { lines }\end{array}$ & Elevated EZH2 HMT expression in breast cancer [19] \\
\hline H3K36me1 and H3K36me2 & Elevated in HL60 leukemia line & $\begin{array}{c}\text { Elevated recruitment of NSD1 HMT translocation in acute myeloid } \\
\text { leukemias [36] }\end{array}$ \\
\hline H4K16ac & $\begin{array}{l}\text { Reduced in MDA-MB231 and MCF7 breast } \\
\text { lines }\end{array}$ & Reduced in patient breast tumors [28] \\
\hline H4K20me2 & Reduced in PC3 prostate line & Reduced in metastatic and castration-resistant prostate cancer [37] \\
\hline H4K2Ome3 & Reduced in H1229 lung line & Reduced in lung carcinoma progression [38] \\
\hline
\end{tabular}


in abundance (data not shown). In fact, the manuscripts first describing these marks on histones have used either extensive fractionation methods or pan-lysine antibodies to first enrich for these species before mass spectrometry detection. As they are low level, we find these marks very difficult to robustly quantify from run to run, and have omitted them from the current studies.

A complementary experiment and limitation in the current work is to map where in the genome each specific histone PTM is localized for each line via ChIP-seq and to cross-reference those genes with interesting histone modification patterns to their transcriptional states. Additionally, future investigations should apply the methods presented in this paper to cancer cells not utilized in tissue culture, but rather collected from patients or harvested across cancer development from primary to metastatic tumors. An interesting application would be in the further subclassification of tumors from the same lineage. Recent studies have shown the utility of gene expression data alone in defining new molecular subtypes in breast cancer tumors [42]. Finally, it is important to emphasize that the chromatin modification landscape is but one facet underlying the complex heterogeneity of cancer. As cancer is not a single disease, it is unlikely for cancer to be explained using a single theoretical framework. An accurate classification must consider other aspects, such as metabolism and global DNA methylation patterns. For example, decreased levels in certain microRNAs, such as miR101 and miR214, result in the overexpression of EZH2 in cancer [43,44], and thus factors governing mRNA stability and translation should also be measured.

\section{Conclusion}

In this report, we applied comprehensive transcriptomic and proteomic analyses with an emphasis on chromatin modification patterns to classify 24 commonly used cell lines, the majority of which are cancerous. Our results support the hypothesis that chromatin states, as defined by the expression levels of both histone PTMs and the associated enzymes, can serve as a basis for the characterization of different cancer types. By systematically and unambiguously quantifying the major histone $\mathrm{H} 3$ and $\mathrm{H} 4$ modifications, one can determine which specific histone modification exhibits the most interesting trends, whether in terms of relative enrichment or in terms of co-variation across similar lines. Bi-clustering analysis showed an overall correlation between the abundance of many histone PTMs and the expression of relevant enzymes, illustrating the complimentary nature of proteomic and transcriptomic data. The techniques and results of this report should be readily extended to nontissue culture and clinical contexts. Finally, while we recognize that not all molecular processes underlying cancer are necessarily related to chromatin-related effects, we believe that the heterogeneity of the histone code itself in terms of its chemical structures and associated functions should offer a uniquely informative vantage into cancer biology.

\section{Methods \\ Cell culture}

The 24 cell lines used in this study are described in Table 1. All lines were cultured at $37^{\circ} \mathrm{C}$ in $5 \% \mathrm{CO}_{2}$, with media supplemented with $1 \%$ penicillin/streptomycin, $1 \%$ glutamax and $10 \%$ fetal bovine serum. For harvesting, suspension cells were centrifuged at $200 \mathrm{~g}$ at room temperature, washed with $1 \times \mathrm{PBS}$, and flash frozen in liquid nitrogen for long-term storage at $-80^{\circ} \mathrm{C}$. Adherent cells were incubated with $10 \times$ trypsin + EDTA for $\leq 5$ minutes when the digestion was quenched with serum-containing media, washed with $1 \times$ phosphate buffered saline, and flash frozen using liquid nitrogen for long-term storage at $-80^{\circ} \mathrm{C}$.

\section{Histone protein extraction and preparation for MS analysis}

All tissue culture lines were similarly processed for histone extraction [45], and the resulting histones were processed for mass spectrometric analysis as described previously [6].

\section{MS analysis/data analysis}

Histone peptides were loaded via autosampler onto a fused silica capillary for reversed phase high performance liquid chromatography as described previously [6], and electrosprayed into a hybrid linear quadrupole ion traporbitrap (ThermoFisher Scientific, Carlsbad, CA, USA ) as previously described. For each line, at least three replicates were performed. Mass spectrometric files for the lines can be accessed (Additional file 8) on the TRANCHE database (https://proteomecommons.org/tranche/). Statistical analyses were performed using MATLAB (R2012a). The LCMS/MS data sets were analyzed using software that has previously been described elsewhere $[17,46]$. Briefly, an optimization-based model considers the MS isotopic distribution, MS/MS fragment ions and relative peptide hydrophobicity relationships to simultaneously identify and quantify (based on integrated peak areas) all modified forms of the same histone peptide. All charge states for modified peptides were included in the analysis, and the abundance of isobaric co-eluting modified forms were deconvoluted based upon tandem MS data as previously described [46]. All reported identifications were validated by manual inspection of the LC-MS/MS data. 


\section{In-house designed microarray}

Agilent's eArray (Agilent Technologies, Inc., Cedar Creek, TX, USA) was employed to design oligo probes and assemble a $22 \mathrm{~K}$-feature microarray. A customized set of 224 histone modifying genes (HAT, HDAC, HMT and HDM) and 551 house-keeping genes were selected to supplement a background consisting of the Agilent Human 1A gene set (Additional file 9). Four different probes were selected for each of the customized gene sets using vendorsupplied probe design processes and associated algorithms. A full list of the probes and features are available for download (Additional file 9).

\section{mRNA extraction and preparation for microarray analysis}

Total RNA was isolated from all cell pellets by the RNeasy RNA isolation kit (Qiagen Sciences, Germantown, MD, USA, ). Equal amounts of RNA isolated from two duplicate wells were combined before the complimentary RNA (cRNA) amplification. The cRNA was then amplified using the Agilent low RNA input linear amplification kit (Agilent Technologies). The quantity and quality of cRNA were evaluated by capillary electrophoresis using an Agilent Technologies 2100 Bioanalyzer. Probe labeling and microarray hybridizations were performed as described in the Agilent 60-mer oligo microarray processing protocol (Agilent Technologies). Cy3-labeled probes derived from each of the 24 cell lines were co-hybridized against Cy5-labeled probes derived from a common reference RNA sample on the in-house designed oligonucleotide array described above. The common reference RNA consisted of a pooling of RNA isolated from all 24 cell lines; thus ensuring that the common reference probes were produced in the same fashion as the other probes, apart from the incorporation of different fluorescent dyes. Slides were scanned with an Agilent microarray scanner and image analysis performed using Agilent Feature Extractor Software. GeneSpring (Agilent Technologies, Inc., Santa Clara, CA, USA) v.9.0 was used to extract mRNA expression data for a total of 4,893 human genes, including the custom gene set; these mRNA expression data were used for correlation and functional analyses downstream.

\section{Tumor xenograft}

All animal work was performed in accordance with the guidelines of the Institutional Animal Care and Use Committee of Princeton University under approved protocols. For tumor formation assays, MDA-MB231 cells were harvested from tissue culture and resuspended at a concentration of $1 \times 10^{7} \mathrm{cells} / \mathrm{ml}$ in PBS. An incision was made in the abdomen of female athymic Ncr-nu/nu mice and $1 \times 10^{5}$ cells $(10 \mu \mathrm{l})$ were injected into the \#4 mammary fat pad of each mouse. Noninvasive bioluminescent imaging (BLI) was performed weekly using an
IVIS 200 Imagine System (Caliper Life Sciences, Alameda, CA USA) to quantify tumor burden over time. BLI data analysis was performed with Living Image Software (Xenogen, Alameda, CA USA) by measuring photon flux in the region of interest. Data were normalized to the signal obtained immediately after injection (Day 1).

\section{Reverse transcription and quantitative PCR}

Total RNA was isolated using the RNeasy kit (Qiagen Sciences) and reverse-transcribed with the Superscript III kit (Invitrogen Life Technologies Co., Carlsbad, CA USA) following the manufacturer's instructions. Quantitative PCR was performed in triplicate using the SYBR Green PCR Master Mix (Applied Biosystems, Warrington, UK) with the ABI Prism 7900HT thermocycler (Applied Biosystems). Raw EZH2 expression levels were normalized to GAPDH expression levels. The following primers were used for qPCR: human EZH2 forward (5'-GTGGAGCCGCTGA CCATTGGG-3') and reverse (5'-CCTGCCACGTCAGAT GGTGCC-3'), and human GAPDH forward (5' - GAAGG TGAAGGTCGGAGTC-3') and reverse (5' - GAAGATG GTGATGGGATTTC-3').

\section{Additional files}

\begin{abstract}
Additional file 1: Relative abundance of histone $\mathrm{H} 3$ and $\mathrm{H} 4$ modified peptides across all cell lines and replicates. These additional files are renumbered due to the shift in position of the previous Additional files 1 and 2 in the Methods section to the end of the manuscript.

Additional file 2: Relative abundance of $\mathrm{H} 3 \mathrm{~S} 10$ phosphorylation across the cell lines, normalized across all the $20 \mathrm{H} 39$ to 17 peptides.

Additional file 3: Relative abundance of canonical $\mathrm{H} 2 \mathrm{~A}, \mathrm{H} 2 \mathrm{AZ}$, macroH2A and $\mathrm{H} 2 \mathrm{AX}$ quantified across all the cell lines, approximated by normalizing the different peptides unique to each protein directly to each other.

Additional file 4: Up- and down-regulated enzymes in the HEK293 (neuronal precursor) and U2OS (bone) cell lines.

Additional file 5: Up- and down-regulated enzymes in the HCT116 (colon) and SW480 (colon) cell lines.

Additional file 6: Up- and down-regulated enzymes in the PC3 (prostate), HFF and HeLa (cervical) cell lines.

Additional file 7: Up- and down-regulated enzymes in the MCF7 (breast), PANC1 (pancreatic) and MDa-MB231 (breast) cell lines.

Additional file 8: Mass spectrometric files for the 24 tissue culture cell lines can be accessed with the four hash tags on the TRANCHE database (https://proteomecommons.org/tranche/).

Additional file 9: List of genes probed in custom microarray and their expression in this study, with an overrepresentation of known human histone modifying enzymes among other housekeeping genes for all 24 tissues culture cell lines.
\end{abstract}

\section{Abbreviations}

ac: Lysine acetylation; BLI: Bioluminescent imaging; CRNA: Complementary RNA; EZH2: Enhancer of zeste 2; HAT: Histone acetyltransferase; HDAC: Histone deacetylase; HDM: Histone demethylase; HMT: Histone methyltransferase; LC-MS/MS: Liquid chromatography tandem mass spectrometry; me1: Lysine monomethylation; 
me2: Lysine dimethylation; me3: Lysine trimethylation; PcG: Polycomb-group; PTM: Post-translational modification.

\section{Competing interests}

The authors declare they have no competing interests.

\section{Authors' contributions}

GL, PM, BZ, IF and EC performed mass spectrometry experiments. GL, EC and $B Z$ performed microarray experiments. MAB performed mouse experiments. $\mathrm{GL}, \mathrm{PD}, \mathrm{BZ}, \mathrm{MAB}, \mathrm{EC}, \mathrm{YK}, \mathrm{PT}$ and $\mathrm{BG}$ participated in the conceived experiments, created the study design and performed statistical analyses. GL, BZ, PD and BG drafted the manuscript. All authors read and approved the final manuscript.

\section{Acknowledgments}

BMZ acknowledges funding from the NSF GRFP and Sigma Xi GAR. PAD acknowledges funding from Imperial College London. BAG acknowledges funding from the NIH Innovator grant (DP2OD007447) from the Office of the Director, National Institutes of Health, and a New Jersey Commission on Cancer Research award. YK acknowledges funding from the Brewster Foundation, the Champalimaud Foundation and the National Institutes of Health (R01CA141062).

\section{Author details}

'Department of Molecular Biology, Princeton University, Princeton, NJ 08544, USA. ${ }^{2}$ Department of Chemical Engineering, Imperial College London, London SW7 2AZ, UK. ${ }^{3}$ Constellation Pharmaceuticals, Inc., Cambridge, MA 02142, USA. ${ }^{4}$ Epigenetics Program, Perelman School of Medicine, University of Pennsylvania, Smilow Center for Translational Research, 3400 Civic Center Blvd., Bldg 421, Philadelphia, PA 19104, USA. ${ }^{5}$ Department of Biochemistry and Biophysics, Perelman School of Medicine, University of Pennsylvania, Smilow Center for Translational Research, 3400 Civic Center Blvd., Bldg 421, Philadelphia, PA 19104, USA.

Received: 1 May 2013 Accepted: 18 June 2013

Published: 5 July 2013

\section{References}

1. Hanahan D, Weinberg RA: Hallmarks of cancer: the next generation. Cell 2011, 144:646-674.

2. Alizadeh AA, Eisen MB, Davis RE, Ma C, Lossos IS, Rosenwald A, Boldrick JC, Sabet H, Tran T, Yu X, Powell Jl, Yang L, Marti GE, Moore T, Hudson J Jr, Lu L, Lewis DB, Tibshirani R, Sherlock G, Chan WC, Greiner TC, Weisenburger DD, Armitage JO, Warnke R, Levy R, Wilson W, Grever MR, Byrd JC, Botstein D, Brown PO, et al: Distinct types of diffuse large B-cell lymphoma identified by gene expression profiling. Nature 2000, 403:503-511.

3. Jenuwein T, Allis CD: Translating the histone code. Science 2001, 293:1074-1080

4. Cao R, Wang L, Wang $H$, Xia L, Erdjument-Bromage $H$, Tempst $P$, Jones RS, Zhang Y: Role of histone H3 lysine 27 methylation in Polycomb-group silencing. Science 2002, 298:1039-1043.

5. Dawson MA, Kouzarides T: Cancer epigenetics: from mechanism to therapy. Cell 2012, 150:12-27

6. Leroy G, Chepelev I, DiMaggio P, Blanco MA, Zee BM, Zhao K, Garcia BA: Proteogenomic characterization and mapping of nucleosomes decoded by Brd and HP1 proteins. Genome Bio/ 2012, 13:R68.

7. Dawson MA, Prinjha RK, Dittmann A, Giotopoulos G, Bantscheff M, Chan WI, Robson SC, Chung CW, Hopf C, Savitski MM, Huthmacher C, Gudgin E, Lugo D, Beinke S, Chapman TD, Roberts EJ, Soden PE, Auger KR, Mirguet O, Doehner K, Delwel R, Burnett AK, Jeffrey P, Drewes G, Lee K, Huntly BJ, Kouzarides $\mathrm{T}$ : Inhibition of BET recruitment to chromatin as an effective treatment for MLL-fusion leukaemia. Nature 2011, 478:529-533.

8. French CA, Ramirez CL, Kolmakova J, Hickman TT, Cameron MJ, Thyne ME, Kutok JL, Toretsky JA, Tadavarthy AK, Kees UR, Fletcher JA, Aster JC: BRDNUT oncoproteins: a family of closely related nuclear proteins that block epithelial differentiation and main the growth of carcinoma cells. Oncogene 2008, 27:2237-2242.

9. Filippakopoulos P, Qi J, Picaud S, Shen Y, Smith WB, Fedorov O, Morse EM, Keates T, Hickman T, Felletar I, Philpott M, Munro S, McKeown MR, Wang Y, Christie AL, West N, Cameron MJ, Schwartz B, Heightman TD, La Thangue N,
French CA, Wiest O, Kung AL, Knapp S, Bradner JE: Selective inhibition of BET bromodomains. Nature 2010, 468:1067-1073.

10. Morin RD, Johnson NA, Severson TM, Mungall AJ, An J, Goya R, Paul JE, Boyle M, Woolcock BW, Kuchenbauer F, Yap D, Humphries RK, Griffith OL, Shah S, Zhu H, Kimbara M, Shashkin P, Charlot JF, Tcherpakov M, Corbett R, Tam A, Varhol R, Smailus D, Moksa M, Zhao Y, Delaney A, Qian H, Birol I, Schein J, Moore R, et al: Somatic mutations altering EZH2 (Tyr641) in follicular and diffuse large B-cell lymphomas of germinal-center origin. Nat Genet 2010, 42:181-185.

11. Nikoloski G, Langemeijer SM, Kuiper RP, Knops R, Massop M, Tönnissen ER, van der Heijden A, Scheele TN, Vandenberghe $P$, de Witte $T$, van der Reijden BA, Jansen $\mathrm{JH}$ : Somatic mutations of the histone methyltransferase gene $E Z H 2$ in myelodysplastic syndromes. Nat Genet 2010, 42:665-667.

12. Cha TL, Zhou BP, Xia W, Wu Y, Yang CC, Chen CT, Ping B, Otte AP, Hung MC: Akt-mediated phosphorylation of $\mathrm{EZH} 2$ suppresses methylation of lysine 27 in histone H3. Science 2005, 310:306-310.

13. Tan M, Luo H, Lee S, Lee S, Jin F, Yang JS, Montellier E, Buchou T, Cheng Z, Rousseaux S, Rajagopal N, Lu Z, Ye Z, Zhu Q, Wysocka J, Ye Y, Khochbin S, Ren B, Zhao Y: Identification of 67 histone marks and histone lysine crotonylation as a new type of histone modification. Cell 2011, 146:1016-1028.

14. Yuan W, Xu M, Huang C, Liu N, Chen S, Zhu B: H3K36 methylation antagonizes PRC2-mediated H3K27 methylation. J Biol Chem 2011, 286:7983-7989.

15. Zheng Y, Sweet SM, Popovic R, Martinez-Garcia E, Tipton JD, Thomas PM, Licht JD, Kelleher NL: Total kinetic analysis reveals how combinatorial methylation patterns are established on lysines 27 and 36 of histone $\mathrm{H} 3$. Proc Natl Acad Sci USA 2012, 109:13549-13554

16. Rea S, Eisenhaber F, O'Carroll D, Strahl BD, Sun ZW, Schmid M, Opravil S, Mechtler K, Ponting CP, Allis CD, Jenuwein T: Regulation of chromatin structure by site-specific histone H3 methyltransferases. Nature 2000, 406:593-599.

17. DiMaggio PA Jr, McAllister SR, Floudas CA, Feng XJ, Rabinowitz JD, Rabitz $\mathrm{HA}$ : Biclustering via optimal re-ordering of data matrices in systems biology: rigorous methods and comparative studies. BMC Bioinformatics 2008, 9:458-473.

18. Sewalt RG, Lachner M, Vargas M, Hamer KM, den Blaauwen JL, Hendrix T, Melcher M, Schweizer D, Jenuwein T, Otte AP: Selective interactions between vertebrate Polycomb homologs and the SUV39H1 histone lysine methyltransferase suggest that histone $\mathrm{H} 3-\mathrm{K} 9$ methylation contributes to chromosomal targeting of Polycomb group proteins. Mol Cell Biol 2002, 22:5539-5553.

19. Ren G, Baritaki S, Marathe H, Feng J, Park S, Beach S, Bazeley PS, Beshir AB, Fenteany G, Mehra R, Daignault S, Al-Mulla F, Keller E, Bonavida B, de la Serna I, Yeung KC: Polycomb protein EZH2 regulates tumor invasion via the transcriptional repression of the metastasis suppressor RKIP in breast and prostate cancer. Cancer Res 2012, 72:3091-3104.

20. Zippo A, Serafini R, Rocchigiani M, Pennacchini S, Krepelova A, Oliviero $\mathrm{S}$ : Histone crosstalk between H3S10ph and H4K16ac generates a histone code that mediates transcription elongation. Cell 2009, 138:1122-1136

21. Ernst J, Kheradpour P, Mikkelsen TS, Shoresh N, Ward LD, Epstein CB, Zhang $X$, Wang $L$, Issner R, Coyne M, Ku M, Durham T, Kellis M, Bernstein BE: Mapping and analysis of chromatin state dynamics in nine human cell types. Nature 2011, 473:43-49.

22. Peach SE, Rudomin EL, Udeshi ND, Carr SA, Jaffe JD: Quantitative assessment of chromatin immunoprecipitation grade antibodies directed against histone modifications reveals patterns of co-occurring marks on histone protein molecules. Mol Cell Proteomics 2012, 11:128-137.

23. Rothbart SB, Lin S, Britton LM, Krajewski K, Keogh MC, Garcia BA, Strahl BD: Poly-acetylated chromatin signatures are preferred epitopes for site-specific histone H4 acetyl antibodies. Sci Rep 2012, 2:489.

24. Zhang L, Freitas MA, Wickham J, Parthun MR, Klisovic MI, Marcucci G, Byrd JC: Differential expression of histone post-translational modifications in acute myeloid and chronic lymphocytic leukemia determined by high-pressure liquid chromatography and mass spectrometry. J Am Soc Mass Spectrom 2004, 15:77-86.

25. Naldi M, Andrisano V, Fiori J, Calonghi N, Pagnotta E, Parolin C, Pieraccini G, Masotti L: Histone proteins determined in a human colon cancer by high-performance liquid chromatography and mass spectrometry. J Chromatogr A 2006, 1129:73-81. 
26. Fraga MF, Ballestar E, Villar-Garea A, Boix-Chornet M, Espada J, Schotta G, Bonaldi T, Haydon C, Ropero S, Petrie K, lyer NG, Pérez-Rosado A, Calvo E, Lopez JA, Cano A, Calasanz MJ, Colomer D, Piris MA, Ahn N, Imhof A, Caldas C, Jenuwein T, Esteller M: Loss of acetylation at Lys 16 and trimethylation at Lys 20 of histone $\mathrm{H} 4$ is a common hallmark of human cancer. Nat Genet 2005, 37:391-400.

27. Song JS, Kim YS, Kim DK, Park SI, Jang SJ: Global histone modification pattern associated with recurrence and disease-free survival in non-small cell lung cancer patients. Pathol Int 2012, 62:182-190.

28. Elsheikh SE, Green AR, Rakha EA, Powe DG, Ahmed RA, Collins HM, Soria D, Garibaldi JM, Paish CE, Ammar AA, Grainge MJ, Ball GR, Abdelghany MK, Martinez-Pomares L, Heery DM, Ellis IO: Global histone modifications in breast cancer correlate with tumor phenotypes, prognostic factors, and patient outcome. Cancer Res 2009, 69:3802-3809.

29. Tzao C, Tung HJ, Jin JS, Sun GH, Hsu HS, Chen BH, Yu CP, Lee SC: Prognostic significance of global histone modifications in resected squamous cell carcinoma of the esophagus. Mod Pathol 2009, 22:252-260.

30. Biano-Miotto T, Chiam K, Buchanan G, Jindal S, Day TK, Thomas M, Pickering MA, O'Loughlin MA, Ryan NK, Raymond WA, Horvath LG, Kench JG, Stricker PD, Marshall VR, Sutherland RL, Henshall SM, Gerald WL, Scher HI, Risbridger GP, Clements JA, Butler LM, Tilley WD, Horsfall DJ, Ricciardelli C, Australian Prostate Cancer BioResource: Global levels of specific histone modifications and an epigenetic gene signature predict prostate cancer progression and development. Cancer Epidemiol Biomarkers Prev 2010, 19:2611-2622

31. Hamamoto R, Furukawa Y, Morita M, limura Y, Silva FP, Li M, Yagyu R, Nakamura Y: SMYD3 encodes a histone methyltransferase involved in the proliferation of cancer cells. Nat Cell Biol 2004, 6:731-740.

32. Müller-Tidow C, Klein HU, Hascher A, Isken F, Tickenbrock L, Thoennissen N, Agrawal-Singh S, Tschanter P, Disselhoff C, Wang Y, Becker A, Thiede C, Ehninger G, zur Stadt U, Koschmieder S, Seidl M, Müller FU, Schmitz W, Schlenke P, McClelland M, Berdel WE, Dugas M, Serve H, Study Alliance Leukemia: Profiling of histone $\mathrm{H} 3$ lysine 9 trimethylation levels predicts transcription factor activity and survival in acute myeloid leukemia. Blood 2010, 116:3564-3571.

33. Leszinski G, Gezer U, Siegele B, Stoetzer O, Holdenrieder S: Relevance of histone marks H3K9me3 and H4K20me3 in cancer. Anticancer Res 2012, 32:2199-2205.

34. Seligson DB, Horvath S, McBrian MA, Mah V, Yu H, Tze S, Wang Q, Chia D, Goodglick L, Kurdistani S: Global levels of histone modifications predict prognosis in different cancers. Am J Pathol 2009, 174:1619-1628.

35. Sasaki H, Setoguchi T, Matsunoshita Y, Gao H, Hirotsu M, Komiya S: The knock-down of overexpressed EZH2 and BMI-1 does not prevent osteosarcoma growth. Oncol Rep 2010, 23:677-684.

36. Wang GG, Pasillas MPCL, Kamps MP: NUP98-NSD1 links H3K36 methylation to Hox-A gene activation and leukaemogenesis. Nat Cell Biol 2007, 9:804-812.

37. Behbahani TE, Kahl P, von der Gathen J, Heukamp LC, Baumann C, Gütgemann I, Walter B, Hofstädter F, Bastian PJ, von Ruecker A, Müller SC, Rogenhofer S, Ellinger J: Alterations of global histone H4K20 methylation during prostate carcinogenesis. BMC Urol 2012, 12:5.

38. Van Den Broeck A, Brambilla E, Moro-Sibilot D, Lantuejoul S, Brambilla C, Eymin B, Khochbin S, Gazzeri S: Loss of histone H4K20 trimethylation occurs in preneoplasia and influences prognosis of non-small cell lung cancer. Clin Cancer Res 2008, 14:7237-7245.

39. Holm K, Grabau D, Lövgren K, Aradottir S, Gruvberger-Saal S, Howlin J, Saal LH, Ethier SP, Bendahl PO, Stål O, Malmström P, Fernö M, Rydén L, Hegardt C, Borg Å, Ringnér M: Global H3K27 trimethylation and EZH2 abundance in breast tumor subtypes. Mol Oncol 2012, 6:494-506.

40. Tsai WW, Wang Z, Yiu TT, Akdemir KC, Xia W, Winter S, Tsai CY, Shi X, Schwarzer D, Plunkett W, Aronow B, Gozani O, Fischle W, Hung MC, Patel DJ, Barton MC: TRIM24 links a non-canonical histone signature to breast cancer. Nature 2010, 468:927-932

41. Xie Z, Dai J, Dai L, Tan M, Cheng Z, Wu Y, Boeke JD, Zhao Y: Lysine succinylation and lysine malonylation in histones. Mol Cell Proteomics 2012, 11:100-107.

42. Prat A, Parker JS, Karginova O, Fan C, Livasy C, Herschkowitz J, He X, Perou CM: Phenotypic and molecular characterization of the claudin-low intrinsic subtype of breast cancer. Breast Cancer Res 2010, 12:R68.

43. Varambally S, Cao Q, Mani RS, Shankar S, Wang X, Ateeq B, Laxman B, Cao X, Jing X, Ramnarayanan K, Brenner JC, Yu J, Kim JH, Han B, Tan P, Kumar-Sinha C,
Lonigro RJ, Palanisamy N, Maher CA, Chinnaiyan AM: Genomic loss of microRNA-101 leads to overexpression of histone methyltransferase EZH2 in cancer. Science 2008, 322:1695-1699.

44. Derfoul A, Juan AH, Difilippantonio MJ, Palanisamy N, Ried T, Sartorelli V: Decreased microRNA-214 levels in breast cancer cells coincides with increased cell proliferation, invasion and accumulation of the Polycomb Ezh2 methyltransferase. Carcinogenesis 2011, 32:1607-1614.

45. Zee BM, Britton LM, Wolle D, Haberman DM, Garcia BA: Origins and formation of histone methylation across the human cell cycle. Mol Cell Biol 2012, 32:2503-2514

46. Wu Y, Dimaggio PA Jr, Perlman DH, Zakian VA, Garcia BA: Novel phosphorylation sites in the $S$. cerevisiae $\mathrm{Cdc} 13$ protein reveal sew targets for telomere length regulation. J Proteome Res 2013, 12:316-327.

doi:10.1186/1756-8935-6-20

Cite this article as: LeRoy et al.: A quantitative atlas of histone modification signatures from human cancer cells. Epigenetics \& Chromatin 2013 6:20.

\section{Submit your next manuscript to BioMed Central and take full advantage of:}

- Convenient online submission

- Thorough peer review

- No space constraints or color figure charges

- Immediate publication on acceptance

- Inclusion in PubMed, CAS, Scopus and Google Scholar

- Research which is freely available for redistribution

Submit your manuscript at www.biomedcentral.com/submit
C) Biomed Central 